\title{
O fenômeno do ingresso crescente de crianças estrangeiras na escola pública regular do Distrito Federal ${ }^{1}$
}

\author{
Marilena Somavilla Bomfim de ANDRADE ${ }^{2}$ \\ Universidade de Brasilia \\ marilenabomfim@gmail.com \\ Percília Lopes Cassemiro dos SANTOS \\ Universidade de Brasilia \\ cilas7@yahoo.com.br
}

\section{Resumo}

Alunos estrangeiros (AEs) são matriculados nas escolas públicas do Distrito Federal (DF) e frequentam as aulas sem saber o português. Desconhecendo a língua de escolarização, eles têm enfrentado dificuldades que tornam a comunicação inviável, tolhendo-lhes a integração e o desempenho escolar. A finalidade dessa pesquisa foi revisar a legislação que ampara o direito do aluno estrangeiro à matrícula nas escolas da Secretaria de Estado de Educação do DF (SEDF) a fim de que os participantes do processo de ensino conheçam os documentos oficiais que regulam o acesso e a integração dos AEs no sistema público de ensino do DF. O estudo, de natureza investigativa e documental, fundamentou-se nos procedimentos metodológicos do estudo de caso. Os resultados revelaram que, embora a legislação brasileira garanta aos AEs o acesso à educação, os órgãos educacionais do

1 Este artigo procede de uma dissertação de mestrado apresentada ao Programa de Pós-Graduação em Linguística Aplicada da Universidade de Brasília, sob a orientação da Prof. Dr. Percília Santos, Coordenadora do Programa de Ensino e Pesquisa de Português para Falantes de Outras Línguas (PEPPFOL): Disponível em: <http://repositorio.bce.unb.br/handle/10482/4956>.

2 Mestre em Linguística Aplicada, pela Universidade de Brasília.

3 Doutora em Linguística Aplicada, professora do Departamento de Línguas Estrangeiras e Tradução da Universidade de Brasília e coordenadora do Programa de Ensino e Pesquisa em Português para Falantes de Outras Línguas (PEPPFOL). 
DF não têm reconhecido a existência dos problemas oriundos da baixa proficiência linguística em português desses alunos, tampouco suscitado reflexão sobre a questão. Esta pesquisa revelou a demanda por uma política linguística específica dos órgãos reguladores de ensino, garantindo uma intervenção didática particular para implementar o processo de aprendizagem da língua alvo pelos AEs até que consigam acompanhar as séries condizentes com a faixa etária do fluxo escolar, na qual o português é o veículo educacional.

Palavras-chave: aquisição/aprendizagem de segunda língua; ensino de português como segunda língua; política linguística.

\section{Abstract}

Foreign students (FS) are being enrolled in public schools in the Brazilian Federal District (Distrito Federal, DF) even though they don't speak Portuguese. Attending classes without knowing the standard language spoken in school has made communication impossible for them and impaired their academic performance and socialization process. The purpose of this research was to review the Brazilian Law that enforces the right of FS's enrollment in schools of SEDF, in order to make those involved in the educational process acknowledge current Official Documentation, which governs FS' access and integration into the public school system in the DF. The study, investigative and documentary in nature, was based on the methodological procedures of the case study. The results revealed that although Brazilian law guarantees FS' access to education, the educational official agencies in the DF have neither recognized the existence of problems stemming from FS's lack of proficiency in the Portuguese language, nor thought about the issue raised. This survey revealed the demand for a specific language policy of regulators of education in the $\mathrm{DF}$, ensuring a particular didactic intervention to implement the process of learning the target language by the FS, and thus lessening the impact on language barrier until they can keep up with the grades that are suitable for the age range of school transition, where Portuguese is the educational vehicle.

Keywords: second language acquisition/learning; teaching Portuguese as a second language; language policy. 


\section{Introdução}

Em razão dos desafios de cunho social e econômico e novos paradigmas impostos pela globalização percebe-se uma intensificação dos movimentos migratórios mundiais, no qual pessoas de diferentes origens culturais e linguísticas atravessam fronteiras em busca de oportunidades de trabalho e melhores condições de vida do que aquelas encontradas em seus países de origem.

Diante dessa conjuntura, sobressai a posição de liderança que o Brasil vem ocupando no cenário sociopolítico-econômico dos países da América Latina e do Cone Sul. Com efeito, emerge o seu potencial como país ancoradouro de imigrantes e de trabalhadores estrangeiros temporários. E disso decorre que um maior fluxo de estrangeiros advindos de países vizinhos e de além-mar está sendo atraído para o país.

Em geral, esses novos imigrantes vêm ao Brasil à procura de condições laborais e de vida mais favoráveis e, usualmente, quando se estabelecem no país, estão acompanhados de suas famílias, e, se há filhos em idade escolar, estes, por conseguinte, são matriculados na escola regular.

Nesse contexto, os alunos estrangeiros, doravante $\mathrm{AEs}^{4}$, oriundos de minorias linguísticas diversas, têm acesso à escola porque a lei brasileira lhes garante o ingresso no sistema escolar. Quando matriculados, esses alunos precisam estar inseridos nas séries escolares condizentes com sua faixa etária.

O interesse por este estudo surgiu a partir de indagações e busca por respostas de um grupo de professores da rede escolar de ensino fundamental e médio do Distrito Federal (DF). Esses professores atendem em suas salas de aula alunos estrangeiros falantes de outras línguas, que ingressaram no sistema escolar sem o indispensável domínio da língua portuguesa. Há que se considerar situações semelhantes que já observamos em outros países, como Portugal, por exemplo, historicamente conhecido como país de

4 Alunos estrangeiros no escopo deste estudo são aqueles que frequentam a escola pública do Distrito Federal sem nenhuma ou baixíssima proficiência em português, a língua de escolarização. 
emigração, tornou-se, a partir da década de 1970, um país de imigração, quando se verificou um aumento significativo de imigrantes oriundos, a princípio, dos países africanos, seguidos daqueles dos países do leste europeu. Nesse sentido, observemos o que afirma Bernardo (2006, p. 8):

$\mathrm{Na}$ escola, os alunos, filhos de imigrantes, entram em contacto com uma língua que não é a Materna. $O$ português para esses alunos acaba por assumir um estatuto diferente, pois nem é a sua língua materna, nem é uma língua estrangeira, mas sim uma Língua Segunda. [...] Sem a aprendizagem dessa Língua Segunda, o aluno estrangeiro não consegue ter sucesso escolar, não só na disciplina de Português, como também em todas as outras disciplinas. Como consequência, não consegue se integrar dentro e fora da escola.

A aprendizagem da língua portuguesa, nesse caso, assume uma importância crucial, pois é a ferramenta necessária para que esses alunos possam alcançar integração na sociedade à qual agora pertencem.

No Brasil, o impacto dessas matrículas na vida da escola tem demonstrado, no entanto, que as nossas instituições de ensino regular ainda não estão preparadas para receber os AEs, que, em geral, fazem parte das minorias linguísticas que encontramos nas escolas e que não recebem qualquer manifestação de tratamento especial ao qual têm direito. A escola parece ignorar o fato de que a ausência de bons resultados acadêmicos desses alunos esteja diretamente relacionada à baixíssima ou nenhuma proficiência linguística em português. $\mathrm{O}$ desconhecimento da língua de escolarização pelos AEs não tem suscitado reflexão, por parte da escola, sobre a situação desses alunos e de seus professores e, portanto, não lhes tem conferido visibilidade.

Verifica-se, igualmente, que há reciprocidade na forma como se estabelece o acesso à matrícula dos AEs na escola pública do Distrito Federal. Esses alunos têm sido matriculados e frequentam as salas de aula sem saber o português. A escola não faz muito por eles que são matriculados sem conhecer a língua de instrução, e, em consequência disso, enfrentam dificuldades de toda ordem - a comunicação fica inviável, a integração 
social e o resultado acadêmico tolhidos. Dessa forma, corrobora Bernardo (2006, p. 7), "O domínio da Língua Portuguesa é factor preponderante na obtenção de sucesso escolar dos alunos de diversas etnias e/ou culturas".

Segundo Caldeira et al. (2004, p. 7), “as mudanças na sociedade implicam novos e constantes desafios para as escolas", sobretudo no que se refere à busca de soluções para a integração à escola dos AEs que ali ingressam e cuja língua materna não é o português.

A responsabilidade pelo ensino de português aos AEs para o bom aproveitamento escolar e para a não interferência no andamento do ensino aos alunos nacionais vai além da competência da escola. São necessárias ações das autoridades educacionais propícias à integração escolar desses alunos para impedir que se afastem da língua e da cultura do país que os acolhe.

Dessa forma, reconhecemos que há que se aconselhar aos órgãos reguladores da educação no Distrito Federal, em particular à Secretaria de Estado de Educação do DF (SEDF), sugerindo-lhes a implementação de políticas linguísticas que se proponham ir além da mera inclusão dos AEs no sistema educacional como cumprimento do direito à educação, mas que visem, sobretudo, adaptar esses alunos à aprendizagem da língua-alvo antes do início do ano letivo, ou durante o mesmo período, a fim de lhes garantir os meios para atingirem o sucesso escolar. Outra ação educacional preventiva e necessária para se alcançar esse objetivo é a capacitação de professores para ministrarem o português como Segunda Língua (L2) ${ }^{5}$ aos alunos estrangeiros.

\section{O enfoque, a metodologia e o escopo desse estudo}

É no ambiente linguístico de uma sala de aula, onde a maioria dos alunos são falantes nativos de português e a instrução é direcionada a eles, que os AEs estão aprendendo a segunda língua. Lightbown e Spada (2006)

5 Entende-se por Segunda Língua (L2) a língua que se aprende no país onde ela é o veículo de comunicação. 
afirmam que é nesse contexto específico, no qual os AEs, que representam a minoria linguística em sala de aula, estão inseridos, é que eles têm o contato maior com a segunda língua. Muitas vezes, é a partir desse primeiro contato que eles começam a usar a L2 para a comunicação além dos muros da escola.

Frente a essa realidade, o acolhimento desses alunos na escola coloca um desafio: o de integrá-los ao processo de escolarização para que lhes seja garantida as mesmas oportunidades de progresso escolar que tem a maioria dos alunos nativos e, para tanto, deve assegurar-lhes o direito ao ensino da língua portuguesa, que lhes proporcionará, conforme enfatiza Barbulescu (2005, p. 4), “a capacidade de expressão e compreensão da língua portuguesa, como instrumento de plena integração".

Essa pesquisa, de natureza investigativa e documental, buscou seguir os procedimentos metodológicos do estudo de caso, segundo o enquadre qualitativo. Como esclarece Gil (2002), o estudo de caso parte do interesse em observar a ocorrência de algum fenômeno no campo social, como o presente estudo observou o fenômeno do ingresso crescente de crianças estrangeiras na escola pública regular do Distrito Federal. E, como acrescenta Stake (1994), por ser o estudo de caso, simultaneamente processo e produto, vai captando as expressões da realidade do objeto de estudo e, ao mesmo tempo, vai construindo o produto dessa aprendizagem.

A asserção anterior confirma a opção por delimitar o escopo dessa pesquisa à análise documental da legislação, geral e específica, que atribui à escola a função de matricular e dar tratamento especial ao aluno estrangeiro, e, portanto, enquanto processo, pensamos que poderia ser relevante aos participantes do sistema de ensino no qual os AEs estão inseridos conhecer os excertos dos documentos legais que regulam o acesso e a integração dos alunos estrangeiros no sistema educacional do Distrito Federal, no âmbito da SEDF.

Ante a realidade que enfrentam os AEs na escola pública do Distrito Federal, constata-se que há um descompasso entre o aluno estrangeiro matriculado em uma determinada série escolar e o seu nível de proficiência 
linguística em português, para acompanhar o conteúdo curricular da mesma série, e que essa ocorrência tem interferido na aprendizagem do aluno nas diversas disciplinas do currículo e na sua integração à escola.

\section{Diversidade cultural e linguística presentes na escola}

A diversidade cultural e linguística hoje presente nas escolas da rede pública de ensino do DF está representada pelas crianças estrangeiras que falam outras línguas e provêm de minorias étnicas das mais variadas origens. São filhos de estrangeiros cujas famílias escolheram o Brasil como país de adoção por razões acadêmicas, laborais ou outras, e que imigraram para cá em busca de melhores dias.

Considerando o direito à educação que nas sociedades democráticas o Estado garante a qualquer cidadão, Gouveia e Solla (2004, p. 28) propõem que "se pretendemos que a democratização do ensino seja uma realidade, o sistema educativo tem de ser capaz de lidar com a heterogeneidade social, cultural e linguística que caracteriza a comunidade escolar na nossa sociedade”. A população escolar, na grande maioria dos países, do ponto de vista cultural e linguístico, reúne alunos estrangeiros de diversas procedências. Essa confluência de culturas e línguas tem ocorrido em função dos efeitos da economia globalizada, que impulsiona o movimento das pessoas, diminuindo distâncias e aumentando o contato entre povos e seus diferentes modos de viver. Segundo Mendes e Caels (2003, p. 2), "recai sobre a escola a imensa responsabilidade de acolher, de modo inclusivo, a diversidade linguística e preparar os cidadãos e a sociedade para a diversidade linguística”.

Há que se ressaltar que a escola, ao não valorizar a diversidade de seus alunos estrangeiros, destacando-a, segundo elabora Bernardo (2006, p. 4), "como elemento dinamizador e enriquecedor na interação entre pessoas e os grupos humanos", estará assumindo uma postura discriminatória, etnocêntrica e preconceituosa, numa oposição frontal à política de inclusão escolar que acolhe o multiculturalismo e rechaça atitudes racistas e os preconceitos étnicos. 
É necessário atentar que, frente à intolerância acima descrita, os alunos estrangeiros, segundo Coelho (2003, p. 8), "podem estar vivenciando gestos e sentimentos de desvalorização e marginalização" pela escola, professores e colegas de turma, o que altera o equilíbrio emocional e interfere na aprendizagem.

Reconhecemos, portanto, que compete à escola valorizar a diversidade cultural elinguística dos alunos estrangeiros, respeitando a diferença, aidentidade étnica, o sistema de crenças e valores ao qual pertencem e, principalmente, assegurando-lhes o direito à aprendizagem da língua portuguesa.

Visando a integração escolar e social dos AEs, a escola deveria adotar uma política interna de idioma mais acolhedora, que provesse meios para ajudá-los a superar mais eficazmente as dificuldades de aprendizagem da língua portuguesa. Por exemplo, a escola poderia proporcionar ao AE um acompanhamento pedagógico. Essa medida fornece aos professores, aos pais e aos alunos um retrato mais fiel para se detectar as dificuldades e, assim, agir mais pontualmente para tentar saná-las.

\section{Aquisição de português por alunos falantes de línguas minoritárias}

Há uma crença generalizada de que os falantes de outras línguas exclusivamente por estarem em contato com a língua portuguesa em solo brasileiro, antes mesmo de chegarem à escola, já a terão aprendido "na prática”(GRANIER, 2000).

Entretanto, o referencial teórico no qual se embasa esta pesquisa nos mostra o contrário, isto é, os mecanismos de aprendizagem da segunda língua não se igualam àqueles que permitem a aquisição da primeira língua. De acordo com Mateus et al. (2009, p. 130), a aquisição da segunda língua é específica e exige tempo por que

implica adquirir um novo sistema de sons, um vasto vocabulário novo, um conhecimento pragmático associado a um novo conjunto de regras gramaticais e, muitas vezes, uma construção diferente do discurso. 
De acordo com Pessini (2003), a baixa proficiência na língua de interação em sala de aula per se já coloca o aluno estrangeiro numa relação de desigualdade com os demais, em que as chances para um desenvolvimento social e acadêmico serão mínimas, a menos que se tomem providências para superar a limitação imposta pela barreira linguística.

\section{A praxis do professor e os alunos estrangeiros}

A questão principal trazida pelos professores é o da prática pedagógica individualizada para atender a necessidade do aluno estrangeiro em sala de aula. Nesse contexto, os professores sentem-se desprovidos de uma competência pedagógica específica para ensinar seus alunos estrangeiros. Há que se ressaltar que o termo "aluno estrangeiro" aqui utilizado refere-se àqueles alunos falantes de outras línguas que ainda não têm o domínio da língua portuguesa.

Esses professores afirmam não terem recebido em seus cursos de formação sequer indícios de estratégias para lidar com alunos estrangeiros em salas de aula, onde também se encontram os outros alunos falantes nativos do português que, por sua vez, apresentam dificuldades linguísticas de naturezas diferentes.

Além disso, percebe-se também que não há atualmente cursos de formação continuada oferecidos pela SEDF a fim de orientar os profissionais que lidam diretamente com esses alunos. Isso tem ocasionado a sensação de impotência desses professores, pois, por mais que procurem adequar suas metodologias de ensino para ajudar o aluno estrangeiro a superar os problemas de aprendizagem, seus esforços resultam infrutíferos.

O professor da escola de ensino fundamental e médio quando atende em sua sala de aula o aluno estrangeiro, na maioria das vezes, não tem a formação e a experiência para adotar uma atitude consciente e assertiva em prol da aquisição de português como segunda língua (doravante PL2) pelo aluno estrangeiro.

Esse professor não é necessariamente um especialista em língua portuguesa; por mais que seja um falante nativo do português, sua formação 
acadêmica é oriunda de outras áreas do conhecimento, afora o português. E mesmo quando o professor é de português língua materna (doravante PLM), é necessário salientar que a construção da prática docente desse professor diverge daquele de PL2. Este, além da sua formação em PLM, adquiriu conhecimentos específicos nas áreas de aquisição e ensino/aprendizagem de L2. A este, coube ler, discutir e refletir acerca da especificidade do ensino do português como segunda língua para falantes de outras línguas. A formação básica e a prática pedagógica do professor de PL2, conforme acrescenta Mateus et al.(2009, p. 127), contempla:

as estratégias do ensino do Português como língua segunda [...] os mecanismos que entram na aquisição de uma língua que é "segunda" em relação àquela com que se aprendeu a falar, mas cujo domínio se torna imprescindível para obter êxito escolar e social.

Ao tratar alunos estrangeiros com pouca ou baixíssima proficiência em língua portuguesa, que ainda estão em processo de aquisição, como falantes da língua majoritária e colocá-los, sem alternativa, em turmas voltadas para a formação acadêmica de falantes nativos, cursando as mesmas disciplinas, observam-se diversos problemas, dentre eles o não cumprimento do programa projetado para cada disciplina, o pouco aproveitamento e o baixo desempenho do aluno estrangeiro em situação de L2.

\section{O que prevê a legislação}

$\mathrm{O}$ enquadramento legal que legitima o direito às especificidades de ensino as quais faz jus o aluno estrangeiro, pertencente ao sistema escolar da SEDF, com baixíssima proficiência em língua portuguesa, ainda que este estudo não esgote todas as interpretações e legislações pertinentes à matricula destes alunos, resume-se às seguintes leis e resoluções que serão examinadas a seguir. 


\subsection{A Constituição da República Federativa do Brasil}

A política de inclusão educacional no Brasil está amparada pela Constituição Brasileira de 1988 nas disposições que garantem o direito de educação para todos e o respeito às diferenças. Entretanto, é principalmente a partir dos anos 1990 que as conquistas do movimento da escola para todos se fortalece em nível mundial. Segundo Freitas (2006, p. 38), "os movimentos de estruturação de escolas inclusivas de vários países, dentre eles o Brasil", se consolidaram por meio de documentos e acordos internacionais. Dentre eles se destacam aqueles ratificados pela Conferência de Jomtien, na Tailândia, em 1990, e os princípios e resoluções da Declaração de Salamanca, na Espanha, em 1994.

Na perspectiva de Alves e Barbosa (2006, p. 22), a organização do trabalho curricular, para estar alinhada ao conceito de inclusão na escola e valorização da diversidade, coloca o aluno e não o conteúdo no centro dessa nova ordem e, para tanto, propõem os seguintes pressupostos:

O trabalho baseado na concepção da educação inclusiva reconhece e valoriza, sobretudo as características individuais do processo de construção de conhecimento de cada aluno [...] enfatiza as possibilidades de desenvolvimento acadêmico e sucesso escolar, [...] pressupõe [...] uma organização que considere as necessidades de todos os alunos, garantindo outros possíveis caminhos, que possam favorecer a construção da autonomia social e educacional.

A Constituição Federal, no Título VIII - Da Ordem Social, Capítulo III - Da Educação, Da Cultura e Do Desporto, Seção I - Da Educação, Artigos 205 e 206 e incisos, garantem a todos o direito ao acesso ao ensino e à igualdade de oportunidades para o sucesso escolar, visando à completa integração à sociedade e a produtividade no trabalho.

Art. 205. A educação, direito de todos e dever do Estado e da família, será promovida e incentivada com a colaboração da sociedade, visando ao pleno desenvolvimento da pessoa, seu preparo para o exercício da cidadania e sua qualificação para o trabalho. 
Art.206. O ensino será ministrado com base nos seguintes princípios: I - igualdade de condições para o acesso e permanência na escola;

II - liberdade de aprender, ensinar, pesquisar e divulgar o pensamento, a arte e o saber;

III - pluralismo de idéias e de concepções pedagógicas, e coexistência de instituições públicas e privadas de ensino.

\subsection{O Estatuto da Criança e do Adolescente}

$\mathrm{Na}$ prática, o Estatuto da Criança e do Adolescente dispõe sobre a proteção integral e prioritária à criança e ao adolescente; resgata juridicamente a cidadania e a atenção universalizada a todas as crianças e adolescentes e imputa à família, à sociedade e ao Estado a responsabilidade de garantir os direitos das crianças e adolescentes e de socializá-los (RICCI, 2003).

Em prosseguimento, a legislação específica do direito à matrícula do aluno estrangeiro em escola pública brasileira no Estatuto da Criança e do Adolescente está disposta no Capítulo IV - Do Direito à Educação, à Cultura, ao Esporte e ao Lazer, Artigos 53 e 54, que determinam:

Art. 53. A criança e o adolescente têm direito à educação, visando ao pleno desenvolvimento de sua pessoa, preparo para o exercício da cidadania e qualificação para o trabalho, assegurando-se-lhes:

I - igualdade de condições para o acesso e permanência na escola;

Art. 54. É dever do Estado assegurar à criança e ao adolescente:

I - ensino fundamental, obrigatório e gratuito, inclusive para os que a ele não tiveram acesso na idade própria;

II - progressiva extensão da obrigatoriedade e gratuidade ao ensino médio;

\subsection{A Lei de Diretrizes e Bases da Educação Nacional}

A Lei de Diretrizes e Bases (LDB) ${ }^{6}$, ou Lei no 9.394, de 20 de dezembro de 1996, embora não explicite no texto a redação da obrigatoriedade da

6 A Lei de Diretrizes e Bases da Educação Nacional está disponível em: <http:// www.planalto.gov.br/ccivil_03/LEIS/19394.htm>. 
matrícula de aluno estrangeiro na escola pública, deixa evidente que o aluno - que pela própria característica de ser estrangeiro, e que nessa condição apresenta diversidade de necessidades, principalmente a da transposição da barreira linguística - tem direito ao atendimento especial por parte da escola. $\mathrm{O}$ direito às especificidades de ensino as quais faz jus o aluno estrangeiro, que é inserido no sistema escolar da SEDF com baixíssima proficiência em língua portuguesa, está implícito nas seguintes disposições da LDB: Título II - Dos Princípios e Fins da Educação Nacional, Artigos $3^{\circ}$, incisos I, II, III e IV:

Art. $3^{\circ}$. O ensino será ministrado com base nos seguintes princípios: I - igualdade de condições para o acesso e permanência na escola; II - liberdade de aprender, ensinar, pesquisar e divulgar a cultura, o pensamento, a arte e o saber;

III - pluralismo de ideias e de concepções pedagógicas;

IV - respeito à liberdade e apreço à tolerância;

Segundo o que estipulam os Artigos 12, incisos V, e 13, incisos III e IV, o aluno estrangeiro matriculado na escola e que não tem o domínio da língua de interação está amparado legalmente a receber aulas de recuperação. Compete à escola, e tem o amparo legal para tanto, prover a ele os meios necessários para transpor a barreira linguística que impugna qualquer incentivo à recuperação de conteúdo das outras disciplinas. Sem ter acesso à única ferramenta-chave que é a aprendizagem da língua portuguesa, qualquer aula repetidora de conteúdos não assimilados resulta inútil.

Art. $12^{\circ}$. Os estabelecimentos de ensino, respeitadas as normas comuns e as do seu sistema de ensino, terão a incumbência de: $\mathrm{V}$ - prover meios para a recuperação dos alunos de menor rendimento;

Art. $13^{\circ}$. Os docentes incumbir-se-ão de:

III - zelar pela aprendizagem dos alunos;

IV - estabelecer estratégias de recuperação para os alunos de menor rendimento 
A LDB dá enfoque ao papel principal que tem a escola na condução do processo educacional, dotando-a de ampla autonomia de organização. Esse referencial é também corroborado nos PCNs, Volume 1, intitulado Introdução (BRASIL, 1997, p. 41), que assim orienta:

a escola pode se organizar em séries anuais, períodos semestrais, ciclos, alternância regular de períodos de estudos, grupos nãoseriados com base na idade, competência em outros critérios, sempre que for interesse do processo de aprendizagem. Também os calendários escolares podem ser estabelecidos de forma a adequar-se às peculiaridades locais.

\subsection{A Resolução no $1 / 2005$, do Conselho de Educação do DF}

O Conselho de Educação do Distrito Federal (CEDF) é um órgão consultivo-normativo de deliberação coletiva e de assessoramento superior à SEDF. A sua função precípua é a de estabelecer normas para orientar e organizar o funcionamento do sistema de ensino do DF. Portanto, é da competência do CEDF baixar diretrizes para: regular as instituições educacionais públicas e privadas, no âmbito administrativo, didático e disciplinar; supervisionar, fiscalizar e acompanhar essas instituições; estabelecer critérios para autorização de cursos e credenciamento de instituições e para avaliação da educação (SEEDF, 2002).

Como linha mestra para o amparo legal a que faz jus o aluno estrangeiro, o Art. 118 caput e os $\$ 1^{\circ} \S 2^{\circ}$, da Resolução no $1 / 2005$, é o referencial que norteia e fundamenta esta pesquisa, pois confirma que o aluno estrangeiro matriculado nas escolas da SEDF tem direito também ao tratamento especial que vise prover meios para adaptá-lo aos estudos.

Como a dificuldade intrínseca desse aluno consiste na barreira linguística, pois tem pouco ou baixíssima proficiência na língua de escolarização, é mister que se busquem soluções que visem também o sucesso, e não apenas o seu acesso escolar. Assim, o Artigo 118 determina que:

O aluno provindo de instituição educacional de outro país merecerá tratamento especial para efeito de matrícula e adaptação de estudos. 
$\S 1^{\circ}$. O processo de adaptação não precisa, necessariamente, ser concluído no mesmo período letivo, e, neste caso, a avaliação será específica, abrangendo os estudos realizados pelo aluno.

§2。 É de competência da instituição educacional a análise da documentação dos alunos procedentes do exterior, para fins de prosseguimento de estudos.

\subsection{O Regimento Escolar das Instituições da Rede Pública de Ensino do DF}

No próprio documento acima referido, à página 11, o Artigo $1^{\circ}$ estipula a função do regimento escolar como "o instrumento que regulamenta a organização didático-administrativa das Instituições Educacionais da Rede Pública de Ensino do Distrito Federal". Aqui se encontram informações sobre os diferentes tipos de instituições de ensino de acordo com seu atendimento e sua estrutura organizacional, pedagógica e administrativa.

O Artigo $175, \S 1^{\circ}$ e $§ 2^{\circ}$, está disposto no Capítulo XIV, do Título I, desse regimento, que dispõe sobre a transferência, o aproveitamento de estudos e da adaptação de estudos. No âmbito desta pesquisa, o enfoque está voltado para o direito à matrícula escolar do aluno estrangeiro.

O aluno procedente do exterior recebe tratamento especial quanto à matrícula e adaptação de estudos.

$\S 1^{\circ}$. Cabe à instituição educacional efetuar a equivalência de estudos, podendo ser solicitada a assistência técnica do órgão de inspeção, em caso de dificuldade para sua efetivação.

$\S 2^{\circ}$. A equivalência de curso ou estudos de nível médio realizado integralmente no exterior obedecerá às normas definidas pelo Conselho de Educação do Distrito Federal.

\subsection{O Manual da Secretaria Escolar do Sistema de Ensino do DF}

Este manual é o documento que dá instruções sobre o registro dos dados educacionais referentes ao aluno e à instituição de ensino. No que se 
relaciona à matricula do aluno estrangeiro nas escolas da SEDF, o enfoque é o procedimento número 10 do manual, no qual se encontram todas as etapas necessárias para se proceder à matrícula. No texto desse procedimento, especificamente no item 10.2, no qual constam as Observações, que se encontra em anexo, o teor do documento dispõe sobre a legislação específica da matrícula do aluno estrangeiro quanto à equivalência de estudos, que assegura o tratamento especial que tem direito este aluno, para efeito de matrícula e adaptação dos estudos.

Chamamos a atenção para a resposta unânime dos técnicos da Coordenação de Supervisão Institucional e Normas de Ensino (COSINE), do CEDF e da DRE PP/C quando consultados sobre o tratamento especial, disposto no Art. 118 e $§ 1^{\circ} \S 2^{\circ}$ da Resolução no 1/2005, do CEDF, e no item 10.2 do manual citado, a ser dispensado ao aluno estrangeiro, ao reportarem que não existe no âmbito da SEDF, qualquer legislação que dê instruções específicas ou forneça detalhes sobre o que consiste esse "tratamento especial" a que faz jus o aluno estrangeiro.

Outra seção do manual pertinente à matrícula referida é o Anexo XVIII que trata das estruturas educacionais de vários países.

A matrícula do aluno estrangeiro na escola será efetivada desde que cumprida as exigências de apresentação da documentação do aluno, que consta de: histórico escolar, boletim, currículo ou certificado com visto consular emitido por consulado brasileiro no país de origem ou pelo MRE. Os pais ou responsáveis devem apresentar a tradução oficial dos documentos acima citados, realizada por tradutor público juramentado ou tradução que mereça fé, realizada por embaixadas, consulados, repartições públicas, escolas de línguas ou particulares, exceto parentes (constando o nome do tradutor por extenso, assinatura, número de identidade e $\mathrm{CPF}$ ).

$\mathrm{Na}$ próxima etapa, os documentos são encaminhados à Direção da instituição de ensino, que designará uma comissão para analisar o caso, emitir parecer sobre a correspondência de níveis e modalidades cursadas no exterior e compará-las com a estrutura educacional brasileira, com base nas informações sobre estruturas educacionais de alguns países, constantes 
no Anexo XVIII, já citado e, por fim, observar a faixa etária do aluno e os aspectos pedagógicos que, ao término dessa análise, deverá indicar a série a ser cursada pelo aluno.

\section{Por uma política linguística mais abrangente}

A população escolar, na grande maioria dos países, do ponto de vista cultural e linguístico, reúne alunos estrangeiros de diversas procedências. Essa confluência de culturas e línguas tem ocorrido em função dos efeitos da economia globalizada, que impulsiona o movimento das pessoas, diminuindo distâncias e aumentando o contato entre povos e seus diferentes modos de viver.

Se a meta educacional que orienta a ação pedagógica estiver pautada na cidadania, ela pode disseminar atitudes que contemplem a diversidade presente na escola a fim de que os alunos estrangeiros lá matriculados possam se beneficiar de práticas pedagógicas diferenciadas e superem as dificuldades encontradas. Essa questão é apresentada nos PCNs, Volume 10, intitulado Pluralidade Cultural (BRASIL, 1997, p. 25):

A diversidade marca a vida social brasileira. [...] Os processos migratórios colocam em contato grupos sociais com diferenças de fala, de costumes, de valores, de projetos de vida. Frequentemente, [...] esse processo complexo presente na vida brasileira é ignorado e/ ou descaracterizado [...]. Também na escola, onde essa diversidade está presente diretamente naqueles que constituem a comunidade escolar, essa presença tem sido ignorada, silenciada ou minimizada. São múltiplas as origens da omissão com relação à Pluralidade Cultural.

O desafio para a escola, nesse caso, consiste em atender as necessidades educacionais que lhe apresenta a chegada dos alunos estrangeiros sem o conhecimento da língua portuguesa. Esses alunos encontram dificuldades para se comunicar em sala de aula com seus professores e com os demais colegas. Além disso, sentem-se encabulados por não entenderem o que se 
fala e têm medo de se expressar em português. Em consequência, sentemse desmotivados, não se adaptam às regras da disciplina escolar e acabam por ser discriminados (CALDEIRA et al., 2004).

Compete à escola assumir o compromisso de assegurar ao aluno estrangeiro o direito ao ensino da língua portuguesa, que lhes proporcionará o instrumental imprescindível, conforme enfatiza Mateus et al. (2009, p. 129), "para o seu sucesso educativo e para a sua integração na sociedade de acolhimento".

O sistema educacional do DF, no âmbito específico da SEDF, tem competência para encaminhar o problema dos alunos estrangeiros matriculados, com baixa proficiência em língua portuguesa. Para tanto, há documentos legais que amparam o direito do aluno estrangeiro à matrícula nas escolas da SEDF e regulam não somente o acesso, mas a integração desses alunos ao ambiente educacional.

$\mathrm{O}$ domínio da língua portuguesa é prioridade para o $\mathrm{AE}$ que é matriculado nas escolas da rede oficial do DF. Sem ele, fica inviável o sucesso escolar, a integração social com seus pares em sala de aula e no ambiente escolar em geral.

Portanto, diante dessa realidade cabe promover uma reflexão, uma providência sobre o tipo de política linguística educacional a ser aplicada para o AE matriculado nas escolas públicas do DF, que, a despeito da baixa proficiência na língua de escolarização, faz jus à aprendizagem da segunda língua, para que se possa capacitar esse aluno até o ponto em que ele consiga acompanhar as séries escolares, condizentes com a faixa etária do fluxo comum da escola, na qual a língua majoritária é o veículo de instrução. $\mathrm{O}$ princípio norteador dos instrumentos legais internacionais aqui apresentados, e de outros como esses, conforme elabora Sá (2001, p. 24), é:

a escola inclusiva, isto é, uma escola aberta às diferenças, na qual crianças, jovens e adultos devem aprender juntos, independentemente de suas características, origens, condições físicas, sensoriais, intelectuais, linguísticas ou emocionais, econômicas ou socioculturais. 
A consolidação do Programa Educação Inclusiva no Brasil ocorreu em 2003 ao ser implantado em 144 municípios, espalhados em todos os estados brasileiros e no DF. Esse programa, alinhado às iniciativas internacionais que assumiram a inclusão escolar como política, veio inaugurar uma mudança no enfoque da política educacional no Brasil, que antes tinha como marco conceitual a integração, evoluiu para a política de inclusão na escola (ALVES; BARBOSA, 2006).

Segundo Hingel (2001, p. 1) um dos princípios norteadores da política de inclusão na escola é a "valorização da diversidade". Para ele, investir na educação inclusiva "trata-se de articular mecanismos de apoio e ações que permitam igualar as oportunidades de aprendizagem e conhecimento para todos, respeitando e valorizando a diversidade”. Essa orientação poderia nos indicar que quando se fala em educação inclusiva levam-se em conta as especificidades dos alunos em sala de aula. Em decorrência disso, ao reconhecê-las, deve-se buscar soluções pedagógicas que efetivamente respondam a essas especificidades.

\section{Considerações finais}

O presente estudo tem um caráter incipiente no Brasil, visto que não há muitas pesquisas desenvolvidas na área do ensino do português como segunda língua para alunos estrangeiros, com baixa proficiência em língua portuguesa e que são matriculados na rede pública de ensino básico no Brasil.

É por isso que este documento enfatiza o diálogo, o intercâmbio e a parceria dos órgãos educacionais do DF com a universidade, como forma de a escola abrir-se à atualização, com vistas a reconhecer, em primeiro lugar, as peculiaridades desse tema e, em seguida, a necessidade de programar novas estratégias e ações que assegurem o pleno exercício do direito dos AEs à aprendizagem do português como segunda língua, antes do início do ano letivo ou mesmo durante o período letivo, no turno contrário às aulas.

Poder-se-ia, por exemplo, disponibilizar-se nos Centros Interescolares de Línguas (CILs) ou nas escolas um programa de ensino de PLE 
intensivo, antes de o aluno ingressar no ensino fundamental ou médio, e contratar professores de PL2 para trabalhar com esses alunos estrangeiros. Enfim, poder-se-ia promover a formação continuada dos professores da SEDF em convênio com a Universidade de Brasília, que há tempo dispõe de um programa, como o PEEPFOL ${ }^{7}$, que oferece cursos de PL2 a toda a comunidade estrangeira do DF, bem como cursos de capacitação de professores para atuarem na área de ensino de português como segunda língua. A iniciativa de formar professores para ensinar o PL2 e de capacitálos por meio de cursos rápidos, ministrados por professores universitários especializados nessa abordagem de ensino, deve partir da SEDF.

A solução dos intrincados problemas dos alunos estrangeiros com dificuldades na língua portuguesa vai além da competência da escola. Para encaminhar essa questão, há que se unirem esforços entre os órgãos reguladores da educação no DF e a universidade.

A atual pesquisa buscou despertar o olhar do Poder Público, responsável pela educação no DF, pressupondo-se uma atitude ativa da SEDF, da DRE e das escolas, no sentido de ensinar a língua de escolarização aos AEs, que necessitam ter o domínio do português a fim de que compartilhem, em condições de igualdade, as mesmas oportunidades de aprendizagem dos alunos brasileiros. Dessa forma, a adoção de uma política educacional que vise a integração escolar dos AEs estará combatendo seu insucesso na escola e impedindo que se afastem da língua e da cultura do país que os acolhe e realizando, de fato, a inclusão desses alunos.

\section{Referências}

ALVES, Denise O.; BARBOSA, Kátia A. M. Experiências educacionais inclusivas: refletindo sobre o cotidiano escolar. Experiências Educacionais Inclusivas. Programa Educação Inclusiva: direito à diversidade. Brasília: Ministério da Educação, Secretaria de Educação Especial, 2006. p.

7 Programa de Ensino e Pesquisa em Português para Falantes de Outras Línguas. 
15-23. Disponível em: <http://portal.mec.gov.br/seesp/arquivos/pdf/ experienciaseducacionaisinclusivas.pdf $>$. Acesso em: 24 jul. 2009.

BARBULESCU, Georgiana O ensino do português como lingua estrangeira para alunos de língua romena em Portugal. Monografia - (Pós-Graduação em Ensino de Português Língua Não-Materna) Centro de Estudos Multiculturais, Universidade Internacional de Lisboa, Lisboa, 2005. Disponível em: <www.multiculturas.com/textos/PLNM_romenofonos_ Georgiana-Barbulescu.pdf>. Acesso em: 9 jun. 2009.

BERNARDO, Isabel. A escola multicultural e o ensino do português lingua segunda. Monografia (Pós-Graduação em Ensino de Português Língua Não-Materna) - Centro de Estudos Multiculturais, Universidade Internacional de Lisboa, Lisboa, 2006. p. 1-14. Disponível em: <www. multiculturas.com/textos/escola_multicultural_Isabel-Bernardo.pdf $>$. Acesso em: 3 maio 2009.

BRASIL. Constituição da República Federativa do Brasil. Brasília, DF: Senado, 1988. Disponível em: <www.planalto.gov.br/ccivil_03/ constituicao/constituicao.htm>. Acesso em: 3 jun. 2009.

- Estatuto da criança e do adolescente. Lei no 8.069, de 13 de julho de 1990. Disponível em: <www.planalto.gov.br/ccivil/LEIS/L8069.htm>. Acesso em: 8 jun. 2009.

. Lei de Diretrizes e Bases da Educação Nacional. Lei no 9.394, de 20 de dezembro 1996. Disponível em: <http://www.planalto.gov.br/ccivil_03/ LEIS/19394.htm>. Acesso em: 3 maio 2009.

Ministério da Educação/SEF. PCN - Parâmetros curriculares nacionais: $1^{a}$ a $4^{a}$ série: pluralidade cultural e educação sexual. Volume 10, Secretaria de Educação Fundamental, Brasília, 1997, 164 p. Disponível em: http://portal.mec.gov.br/seb/arquivos/pdf/introdução.pdf>. Acesso em: 3 jun. 2009.

CALDEIRA, Isa; PAES, Isabel; MICAELO, Manuela; VITORINO, Teresa. Aprender com a diversidade: um guia para o desenvolvimento da 
escola. Ministério de Educação: Lisboa, 2004. Disponível em: <http:// www.acidi.gov.pt/docs/publicacoes/entreculturas/guia_diversidade.pdf $>$. Acesso em: 17 maio 2009.

COELHO, Suzana L. B. Educação e Pluralidade, Educação Inclusiva. Instituto Cultiva, p. 8- 9, 2003. Disponível em: <www.w.cultiva.org.br/ texto_publi/educação_inclusiva_semg.pdf>. Acesso em: 6 jun. 2009.

DISTRITO FEDERAL. Secretaria de Estado de Educação. Coletânea de Normas. Brasília, Conselho de Educação do Distrito Federal, 2006, 192 p. Secretaria de Estado de Educação. Manual de Secretaria Escolar do Sistema de Ensino do Distrito Federal. Brasília, Subsecretaria de Planejamento e de Inspeção de Ensino, 2002, 96 p.

. Secretaria de Estado deEducação.Diretrizes Pedagógicas 2009/2013. Brasília, Subsecretaria de Educação Básica, 2008. Disponível em: <http:// www.se.df.gov.br/300/30001007.asp?ttCD_CHAVE=14213>. Acesso em: 8 jun. 2009.

Secretaria de Estado de Educação. Regimento Escolar das Instituições Educacionais da Rede Pública de Ensino do Distrito Federal. 4. ed. Brasília, Subsecretaria de Educação Pública, 2006. Disponível em: <http://www.se.df. gov.br/300/30001007.asp?ttCD_CHAVE=14213>. Acesso em: 8 jun. 2009.

FREITAS, Soraia. N. Uma escola para todos: reflexões sobre a prática educativa. Inclusão: Revista de Educação Especial, Brasília, Secretaria de Educação Especial, p. 37-40, dez. 2006.

GIL, Antônio. C. Como elaborar projetos de pesquisa. São Paulo: Ed. Atlas, 2002. 175 p.

GOUVEIA, Adelina; SOLLA, Luísa. Português lingua do país de acolbimento: Educação Intercultural. 1. ed., Lisboa: Alto Comissariado para a Imigração e Minorias Étnicas (ACIME), 2004. 182 p. Disponível em: <www.entreculturas.pt/Media/Publicacoes/Portugues_lingua_N4.pdf>. Acesso em: 12 abr. 2009. 
GRANIER, Danielle M. Perspectivas na formação do professor de português como segunda lingua. In: ENCONTRO INTERNACIONAL DE PORTUGUÊS - LÍNGUA ESTRANGEIRA, 2. São Paulo. Universidade de São Paulo, São Paulo, 2000.

GROSJEAN, Francois. Life with two languages: an introduction to bilingualism. 1st ed., Cambridge: Harvard University Press, 1982.

HINGEL, Murílio. Apresentação. Educação Inclusiva. Instituto Cultiva, p. 1-2, 2001. Disponível em: <www.w.cultiva.org.br/texto_publi/educação_ inclusiva_semg.pdf>.Acesso em: 15 jul. 2009.

LIGHTBOWN, Patsy M. M.; SPADA, Nina. How Languages are learned. 3rd ed., Oxford: Oxford University Press, 2006.

MATEUS, Maria. H. M.; CAELS, Fausto F. G.; CARVALHO, Nuno. O ensino do Português em contexto multilíngüe - o que aprendemos com o Projecto Diversidade Lingüística, Medi@çôes - Revista Online da Escola Superior de Educação do Instituto Politécnico de Setúbal, v. 1, n. 1, 2009. Disponível em: <http://mediacoes.ese.ips.pt/index.php/mediacoesonline/ article/view/9>. Acesso em: 6 jun. 2009.

MENDES, Maria M. M. S. A.; CAELS, Fausto F. G. Projeto Diversidade Lingüistica na Escola Portuguesa. ILTEC - Instituto de Lingüística Teórico e Computacional, Primeiros Resultados, Direção Geral de Inovação Curricular, Ministério da Educação e Fundação Calouste Gulbenkian, 2003-2005, p. 2-35. Disponível em: <http://www.iltec.pt/divling/index. html>. Acesso: 24 maio 2009.

PESSINI, Márcia P. A aquisição do português escrito por Alex, entre o Paraguaie Brasil: um estudo de caso. Dissertação (Mestrado) - Universidade Estadual de Campinas, Campinas, 2003.

RICCI, Rudá. Estatuto da criança e do adolescente: educação inclusiva. Instituto Cultiva, 2003, pp. 18, Disponível em:

<http://www.cultiva.org.br/texto_publi/educação_inclusiva_semg.pdf>. Acesso: 04 abr. 2009. 
SÁ, Elizabet D. Inclusão Escolar, Educação Inclusiva. Instituto Cultiva, p. 24, 2001. Disponível em: <www.w.cultiva.org.br/texto_publi/educação_ inclusiva_semg[2].pdf>. Acesso em: 1 ago. 2009.

STAKE, Richard. E. Case studies. In: DENZIN, N. K.; LINCOLN, Y. S. (Eds.). The Sage handbook of qualitative research. 3 rd ed. London: Sage, 1994. p. 236-247. 